\title{
Factors associated with exclusive breast-feeding and breast- feeding in Norway
}

\author{
Anne Lene Kristiansen ${ }^{1, *}$, Britt Lande ${ }^{2}$, Nina Cecilie $\varnothing_{\text {verby }}{ }^{3}$ and Lene Frost Andersen ${ }^{1}$ \\ 'Department of Nutrition, Institute of Basic Medical Sciences, University of Oslo, PO Box 1046, Blindern, \\ 0316 Oslo, Norway: ${ }^{2}$ Division of Public Health, Norwegian Directorate of Health, Oslo, Norway: \\ ${ }^{3}$ Faculty of Health and Sport, University of Agder, Kristiansand, Norway
}

Submitted 13 January 2010: Accepted 21 June 2010: First published online 16 August 2010

\begin{abstract}
Objective: To identify factors associated with exclusive breast-feeding and breastfeeding during the first year of life among Norwegian infants.

Design: Data on breast-feeding practices were collected by a semi-quantitative FFQ. Setting: In 2006-2007 about 3000 infants were invited to participate in a populationbased prospective cohort study in Norway.

Subjects: A total of 1490 mothers/infants participated at both 6 and 12 months of age. Results: Exclusive breast-feeding at 4 months was associated with parental education, parity and geographical region, while exclusive breast-feeding at 5.5 months was associated only with maternal age. At both ages, a negative association with exclusive breast-feeding was observed for maternal smoking. Breast-feeding at 6 months was associated with parental education, maternal age and marital status. Breast-feeding at 12 months was associated with maternal education, maternal age and number of children. At both ages, negative associations with breast-feeding were observed for maternal smoking and descending birth weight. At 12 months, a negative association was also observed for having day care by other than the parents.

Conclusions: Even though Norway has an extensive and positive breast-feeding tradition and a maternal leave system that supports the possibility to breast-feed, factors like maternal education, maternal age and maternal smoking are strongly associated with duration of exclusive breast-feeding and breast-feeding. Research to better understand the reasons for inequalities in breast-feeding is needed to facilitate the development of more effective breast-feeding promotion strategies. This again may improve compliance with recommendations and reduce inequalities in infant feeding practices.
\end{abstract}

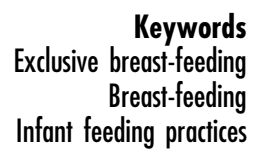

Adequate nutrition during infancy and early childhood is essential to ensure growth, health and development of children to reach their full potential. Breast milk strongly contributes to good health and nutrition of infants. Apart from being an excellent nutritional source for the growing child, breast milk is associated with a reduced risk of many diseases in infants and mothers. A recent review by Duijts et al. ${ }^{(1)}$ points out that a number of studies in industrialised countries suggest that breast-feeding protects infants against overall infections, gastrointestinal and respiratory tract infections. Moreover, Ip et al. ${ }^{(2)}$ reported long-term benefits of breast-feeding for infants to be reduced risk of obesity and type 2 diabetes in later life, and long-term benefits for breast-feeding mothers to be reduced risk of breast and ovarian cancers.

The initiation and duration of exclusive breast-feeding and breast-feeding are influenced by a number of factors. Although the factors that influence the initiation and duration of breast-feeding in developed countries have been broadly studied ${ }^{(3-5)}$, previous studies in these countries have rarely examined the factors associated with exclusive breast-feeding. Breast-feeding and exclusive breast-feeding are, in general, reported to be associated with maternal age, marital status, parental educational level and smoking ${ }^{(6-8)}$. In addition, breast-feeding duration is found to be associated with a wide range of other factors like social status, insufficient milk supply, parity, maternal work situation, infant health problems as well as health service-related factors ${ }^{(5,7)}$.

Since 2001, the $\mathrm{WHO}^{(9)}$ has recommended exclusive breast-feeding for the first 6 months of life. Exclusive breast-feeding is defined as feeding the infant only breast milk without any additional food or drink ${ }^{(10)}$. Norwegian health authorities also recommend exclusive breastfeeding for the first 6 months of life and thereafter gradual introduction of appropriate complementary foods with continued breast-feeding ${ }^{(11)}$. Norway has an extensive and positive breast-feeding tradition ${ }^{(12)}$ and long paid 
maternal leave, which support the possibility of breastfeeding during the first year of life. The parental benefit period is either 46 weeks at $100 \%$ benefit or 56 weeks at $80 \%$ benefit $^{(13)}$.

Based on the data from a large national dietary survey on infant feeding, we have explored factors associated with exclusive breast-feeding and breast-feeding during the first year of life in Norway.

\section{Methods}

\section{Subjects and design}

A nation-wide sample of about 3000 Norwegian infants was established by Statistics Norway. The sample included all infants born in Norway during a 3-week period from 17 April to 8 May in 2006. We assumed that the diet of infants born in April-May was similar to the diet of infants born at other times of the year. The mothers should be born in Norway, Sweden or Denmark. If the child was a twin or a triplet, the parents were asked only to include the oldest. The study had a longitudinal design and was carried out in October-November 2006 and April-May 2007, when the infants were 6 and 12 months of age, respectively. At 6 months, 1986 (67\%) mothers/infants participated. Those who gave a written refusal to participate at 6 months were not invited to participate at 12 months. At 12 months, 1635 (57\%) mothers/infants participated. In the present study, data from 1490 mothers/infants who participated at both 6 and 12 months of age were used for analysis, resulting in a response rate of $52 \%$.

The Regional Committees for Medical Research Ethics approved the study, and informed consent was obtained from the mother/parents.

The mothers received an invitation and a semi-quantitative FFQ (SFFQ) by mail about 2 weeks before the child turned 6 and 12 months of age. To obtain data on the infant's weight and length, parents were asked to bring the questionnaire to the regular 6- and 12-month check-up at the child's health clinic, and then return the completed questionnaire in a pre-paid envelope. At 6 months, one combined thanks/reminder letter and one reminder letter with the questionnaire enclosed were sent out. At 12 months, mothers were contacted once by telephone and received one reminder with the questionnaire enclosed. At 6 and 12 months, those who returned a completed questionnaire were entered in a lottery of ten cheques of approximately US\$800 each and ten cheques of approximately US $\$ 1600$ each.

\section{The semi-quantitative $F F Q$}

Two SFFQ were designed to describe feeding practices at 6 and 12 months of age, respectively, and also to retrospectively describe feeding practices from birth up to the given age. They were based on the SFFQ used in the first Norwegian national dietary survey among infants in
1998-1999 ${ }^{(14,15)}$, and the SFFQ used among 12-montholds had been validated ${ }^{(16)}$. Parents were asked to complete the questionnaires on the day as closely to the child's 6 months or 12 months of age as possible and to describe habitual feeding practices at the given age. Both SFFQ were tested in pilot studies and then revised.

The final SFFQ included forty-two questions at 6 months and fifty-one questions at 12 months. The questions on breast-feeding were related to whether or not the child received breast milk and to the breast milk frequency. Breast milk intake was not quantified. It was also asked when the child stopped receiving breast milk, when it started receiving infant formula/other milk and when the child was introduced to solid or semi-solid foods for the first time. The questions on complementary foods at 6 and 12 months covered approximately fifty and 160 different food items, respectively.

Both SFFQ also provided information on parental educational levels, maternal age, maternal work situation, maternal marital status, maternal smoking and number of children/parity, asthma/allergy in the family, infant gender, infant birth weight, gestational age and day care (only at 12 months).

\section{Classification of breast-feeding}

Based on the WHO definitions on breast-feeding ${ }^{(10)}$, breastfed infants were categorised into exclusively breast-fed and breast-fed. Exclusively breast-fed infants at a given age received only breast milk and had not been introduced to any additional food or drink, not even water, but could have received vitamin-mineral supplements. Breast-fed infants included all infants who received breast milk; both those exclusively breast-fed and those who had been introduced to other drinks than breast milk and/or complementary foods.

\section{Data analysis}

Multiple logistic regression analysis was applied to study exclusive breast-feeding at every month up to 5.5 months of age and breast-feeding at every month up to 12 months of age, in relation to selected parental and infant characteristics. Furthermore, factors associated with the introduction of solid foods were also studied using multiple logistic regression analysis. Multiple logistic regression analysis was applied to those who had information on all maternal/infant characteristics. Results are presented as adjusted OR with 95\% CI. Potential interaction effects were assessed. Statistical significance was tested by the likelihood ratio test. Tests for trends across categories were performed by treating the categories as continuous variables in logistic regression analysis. Maternal and paternal educational levels were coded by eight categories and combined into four categories in the logistic regression analysis: primary and secondary schools, comprehensive school, academy/college/ university of $\leq 4$ years and academy/college/university of $>4$ years. Maternal age, reported as a continuous variable, 
was categorised into three groups: $\leq 24,25-34$ and $\geq 35$ years. Maternal smoking status in pregnancy was coded as yes, yes but quitted and no. Maternal smoking status when the infant was at 6 months old was coded as yes and no. Maternal marital status was coded as married, cohabitant and not married/cohabitant. Ten categories of maternal work situation before childbirth were combined into four categories: full-time, part-time, student and other (including mothers working at home/housewives, mothers on sick leave, unemployed, disabled, on rehabilitation, etc.). Ten categories of maternal work situation when the infant was 12 months were combined into four categories: full-time, part-time, maternity leave and other. Four categories of the number of children/parity were categorised into three groups: one child, two children and three or more children. Five categories of day care at 12 months by others, than parents, were categorised as no (day care by the mother and/or the father) and yes (day care by childminder, kindergarten or grandparents/other care persons). Geographic region was combined into six categories: Capital and surroundings, East, South, West, Middle and North regions. Infant birth weight, reported as a continuous variable, was categorised as $>3500,2500-3500$ and $<2500$ g. Asthma/ allergy in the family was categorised as yes (the infant's mother, father and/or sibling(s) have or have had asthma/ allergy) and no.

With regard to analysis of exclusive breast-feeding at 5.5 months of age, there was a need of collapsing categories for maternal education and maternal age to avoid small subgroups.

We used both results from the univariate analyses (with a criterion of $P<0 \cdot 10$ ) and evidence from the literature to decide which variables should be examined in the multivariate analyses. In the final models, significant variables $(P<0.05)$ were included. However, regardless of the statistical significance level, we decided to include maternal age and maternal education in all the final models. All $P$ values are two-sided, and a 5\% level of significance was used. All statistical analyses were performed with the Statistical Package for Social Sciences statistical software package version $16 \cdot 0$ (SPSS Inc., Chicago, IL, USA).

The results of the analyses of exclusive breast-feeding at 4 and 5.5 months of age, of breast-feeding at 6 and 12 months of age and the introduction of solid foods before 4 months of age are presented. These ages were chosen to study adherence to the recommendations on infant feeding and gave a possibility of comparison with earlier national data from Norway ${ }^{(6)}$.

\section{Results}

Table 1 presents selected characteristics of the infants and their parents. Of the 1490 mothers/infants who participated at both 6 and 12 months of age, $93 \%$ of the mothers completed the questionnaires.
Table 1 Characteristics of infants and their parents ( $n$ 1490)

\begin{tabular}{|c|c|}
\hline Characteristics & Valuet \\
\hline \multicolumn{2}{|l|}{ Infants } \\
\hline Boys/girls & $50 / 50$ \\
\hline Birth weight $(\mathrm{g})$ & $3595(592)$ \\
\hline$>3500$ & 59 \\
\hline $2500-3500$ & 37 \\
\hline$<2500$ & 4 \\
\hline Birth length (cm) & $50 \cdot 3(2 \cdot 6)$ \\
\hline \multicolumn{2}{|l|}{ Gestational age (weeks) } \\
\hline$<38$ & 12 \\
\hline$\geq 38$ & 88 \\
\hline \multicolumn{2}{|l|}{ Mothers } \\
\hline Age (years) & $31 \cdot 2(4 \cdot 8)$ \\
\hline$\leq 24$ & 8 \\
\hline $25-34$ & 68 \\
\hline$\geq 35$ & 24 \\
\hline \multicolumn{2}{|l|}{ Maternal marital status } \\
\hline Married & 47 \\
\hline Cohabitant & 49 \\
\hline Not married/cohabitant & 4 \\
\hline \multicolumn{2}{|l|}{ Smoking during pregnancy } \\
\hline No & 84 \\
\hline Yes, but quitted & 9 \\
\hline Yes & 6 \\
\hline \multicolumn{2}{|l|}{ Smoking } \\
\hline No & 87 \\
\hline Yes & 14 \\
\hline \multicolumn{2}{|l|}{ Education } \\
\hline Primary and secondary schools & 4 \\
\hline Comprehensive school & 29 \\
\hline Academy/college/university ( $\leq 4$ years) & 39 \\
\hline Academy/college/university ( $>4$ years) & 28 \\
\hline \multicolumn{2}{|l|}{ Fathers } \\
\hline \multicolumn{2}{|l|}{ Education } \\
\hline Primary and secondary schools & 7 \\
\hline Comprehensive school & 45 \\
\hline Academy/college/university ( $\leq 4$ years) & 26 \\
\hline Academy/college/university ( $>4$ years) & 22 \\
\hline
\end{tabular}

tPercentages for categorical variables, and means with SD for continuous variables.

$\ddagger$ When the infant was at the age of 6 months.

Ninety-two per cent of the infants were exclusively breastfed at 1 week of age. The proportion of exclusively breastfed infants was $84 \%$ at 1 month of age, $65 \%$ at 3 months and decreased to $48 \%$ at 4 months of age and further down to $13 \%$ at 5.5 months of age (Fig. 1). Only $1.5 \%$ of the infants had never been breast-fed. The breast-feeding level slowly decreased from $96 \%$ at 1 month of age, to $82 \%$ at 6 months of age and to $46 \%$ at 12 months of age (Fig. 1).

Among those who ceased breast-feeding before 6 months, the three most important reasons reported were insufficient milk (40\%), the infant did not want to have breast milk (17\%) and sucking problems (10\%). Between 6 and 12 months of age, the three most important reasons reported for breast-feeding cessation were that the infant did not want to have breast milk (37\%), insufficient milk (20\%) and no specific problems, but did not want to breast-feed any longer (10\%).

\section{Factors associated with exclusive breast-feeding}

Maternal and paternal education, number of children, geographical region and maternal smoking were significantly 
associated with exclusive breast-feeding at 4 months of age (Table 2). Significant positive trends were found for maternal education and number of children. Maternal age was significantly associated with exclusive breast-feeding at 5.5 months of age (Table 3 ) and a significant positive trend was observed. At both 4 and 5.5 months of age the odds of

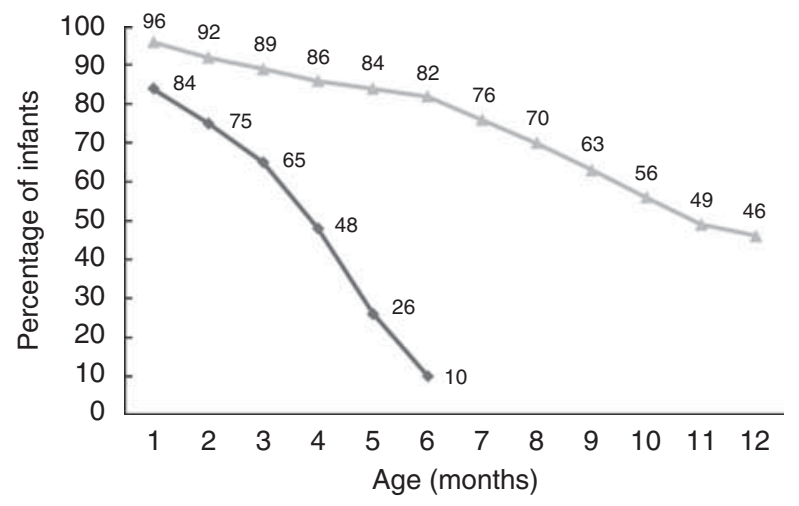

Fig. 1 Exclusive breast-feeding ( $)$ during the first 6 months of life and breast-feeding $(\triangle)$ during the first year of life ( $n$ 1490) exclusive breast-feeding were significantly $(P<0 \cdot 01)$ lower for smoking mothers compared with non-smoking mothers.

In addition, multivariate regression analyses were performed for exclusive breast-feeding at ages 1, 2, 3 and 5 months and the results are summarised in Table 4. Maternal education turned out to be the most stable variable as it was significantly associated with exclusive breastfeeding at most ages. From 3 months of age, maternal smoking was significantly associated with exclusive breastfeeding.

\section{Factors associated with breast-feeding}

Maternal and paternal education, maternal age and marital status were significantly associated with breast-feeding at 6 months (Table 5). Breast-feeding at 12 months was significantly associated with maternal education, maternal age and number of children (Table 5). At both ages, significant negative associations with breast-feeding were observed for maternal smoking and for descending infant birth weight, and at 12 months a negative association was also observed for having day care by other than the parents.

Table 2 Adjusted OR of exclusive breast-feeding at 4 months of age

\begin{tabular}{|c|c|c|c|c|}
\hline \multirow[b]{2}{*}{ Characteristics } & \multirow[b]{2}{*}{$n+$} & \multirow[b]{2}{*}{$\%+$} & \multicolumn{2}{|c|}{$\begin{array}{l}\text { Exclusive breast-feeding at } \\
4 \text { months }\end{array}$} \\
\hline & & & Adjusted OR $\ddagger$ & $95 \% \mathrm{Cl} \neq$ \\
\hline \multicolumn{5}{|l|}{ Maternal education } \\
\hline Primary and secondary schools & 14 & 26 & $1 \cdot 00$ & - \\
\hline Comprehensive school & 138 & 37 & 1.53 & $0.77,3.02$ \\
\hline Academy/college/university ( $\leq 4$ years) & 267 & 50 & $2 \cdot 13$ & $1 \cdot 07,4 \cdot 23$ \\
\hline Academy/college/university ( $>4$ years) & 240 & 63 & $3 \cdot 14$ & $1 \cdot 54,6 \cdot 38$ \\
\hline$P$ trend $\S$ & - & - & 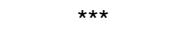 & - \\
\hline \multicolumn{5}{|l|}{ Paternal education } \\
\hline Primary and secondary schools & 42 & 44 & 1.00 & - \\
\hline Comprehensive school & 240 & 40 & 0.67 & $0.42,1.08$ \\
\hline Academy/college/university ( $\leq 4$ years) & 191 & 55 & 0.95 & $0.58,1.57$ \\
\hline Academy/college/university ( $>4$ years) & 186 & 61 & 1.00 & $0.59,1.69$ \\
\hline$P$ trend $\S$ & - & - & NS & - \\
\hline \multicolumn{5}{|l|}{ Maternal age (years) } \\
\hline$\leq 24$ & 26 & 23 & 1.00 & - \\
\hline $25-34$ & 451 & 49 & $1 \cdot 62$ & $0.99,2.67$ \\
\hline$\geq 35$ & 182 & 57 & $1 \cdot 74$ & $1.00,3.04$ \\
\hline$P$ trend $\S$ & - & - & NS & - \\
\hline \multicolumn{5}{|l|}{ Maternal smoking } \\
\hline No & 612 & 52 & $1 \cdot 00$ & - \\
\hline Yes & 47 & 27 & 0.43 & $0.29,0.62$ \\
\hline \multicolumn{5}{|l|}{ Number of children } \\
\hline 1 & 213 & 40 & $1 \cdot 00$ & - \\
\hline 2 & 301 & 55 & $1 \cdot 77$ & $1 \cdot 37,2 \cdot 30$ \\
\hline$\geq 3$ & 145 & 56 & $2 \cdot 00$ & $1 \cdot 41,2 \cdot 82$ \\
\hline$P$ trend $\$$ & - & - & $\star \star \star *$ & - \\
\hline \multicolumn{5}{|l|}{ Geographical region } \\
\hline Capital and surroundings & 179 & 55 & $1 \cdot 00$ & - \\
\hline East & 143 & 42 & 0.69 & $0.50,0.96$ \\
\hline South & 117 & 56 & $1 \cdot 25$ & $0 \cdot 86,1 \cdot 81$ \\
\hline West & 110 & 49 & 0.92 & $0.64,1.33$ \\
\hline Middle & 54 & 45 & 0.73 & $0.47,1 \cdot 15$ \\
\hline North & 56 & 44 & $0 \cdot 71$ & $0.46,1 \cdot 11$ \\
\hline
\end{tabular}

tNumber and percentage of exclusive breast-fed infants within current independent variable. Total number of infants at 4 months of age (n 1343).

‡OR and $95 \% \mathrm{Cl}$ are adjusted for all other variables in the table.

$\S$ Test for linear trend: NS; ${ }^{\star} P<0.05,{ }^{\star \star} P<0.01,{ }^{\star \star \star} P<0.001$ 
Table 3 Adjusted OR of exclusive breast-feeding at $5 \cdot 5$ months of age

\begin{tabular}{|c|c|c|c|c|}
\hline \multirow[b]{2}{*}{ Characteristics } & \multirow[b]{2}{*}{$n+$} & \multirow[b]{2}{*}{$\%+$} & \multicolumn{2}{|c|}{$\begin{array}{l}\text { Exclusive breast-feeding at } \\
\qquad 5.5 \text { months }\end{array}$} \\
\hline & & & Adjusted ORł & $95 \% \mathrm{Cl} \ddagger$ \\
\hline \multicolumn{5}{|l|}{ Maternal education } \\
\hline Primary/secondary/comprehensive school & 46 & 11 & $1 \cdot 00$ & - \\
\hline Academy/college/university ( $\leq 4$ years) & 68 & 13 & $1 \cdot 07$ & $0 \cdot 71,1 \cdot 60$ \\
\hline Academy/college/university ( $>4$ years) & 67 & 18 & $1 \cdot 32$ & $0 \cdot 86,2 \cdot 02$ \\
\hline$P$ trend $\S$ & - & - & NS & - \\
\hline \multicolumn{5}{|l|}{ Maternal age (years) } \\
\hline$<30$ & 46 & 9 & $1 \cdot 00$ & - \\
\hline 30-34 & 71 & 13 & $1 \cdot 29$ & $0 \cdot 86,1.94$ \\
\hline$\geq 35$ & 64 & 20 & $2 \cdot 13$ & $1 \cdot 39,3 \cdot 28$ \\
\hline$P$ trend $\S$ & - & - & 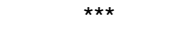 & - \\
\hline \multicolumn{5}{|l|}{ Maternal smoking } \\
\hline No & 172 & 15 & $1 \cdot 00$ & - \\
\hline Yes & 9 & 5 & $0 \cdot 34$ & $0.17,0.68$ \\
\hline
\end{tabular}

Table 4 Factors associated with exclusive breast-feeding during the first 6 months of lifet

\begin{tabular}{|c|c|c|c|c|c|c|c|c|c|}
\hline $\begin{array}{l}\text { Age } \\
\text { (months) }\end{array}$ & $\begin{array}{l}\text { Maternal } \\
\text { education }\end{array}$ & $\begin{array}{l}\text { Maternal } \\
\text { age }\end{array}$ & $\begin{array}{l}\text { Maternal } \\
\text { smoking }\end{array}$ & $\begin{array}{l}\text { Birth } \\
\text { weight }\end{array}$ & $\begin{array}{l}\text { Paternal } \\
\text { education }\end{array}$ & $\begin{array}{l}\text { Number of } \\
\text { children }\end{array}$ & $\begin{array}{l}\text { Geographical } \\
\text { region }\end{array}$ & $\begin{array}{l}\text { Marital } \\
\text { status }\end{array}$ & $\begin{array}{l}\text { Asthma/ } \\
\text { allergy }\end{array}$ \\
\hline 1 & $x$ & & & $x$ & & & $x$ & & \\
\hline 2 & $x$ & & & $x$ & & & $x$ & $x$ & \\
\hline 3 & $x$ & & $x$ & $x$ & $x$ & $x$ & & & $x$ \\
\hline 4 & $x$ & & $x$ & & $x$ & $x$ & $x$ & & \\
\hline 5 & $x$ & $x$ & $x$ & & & $x$ & & & \\
\hline $5 \cdot 5$ & & $x$ & $x$ & & & & & & \\
\hline
\end{tabular}

†Total number of infants ( $n$ 1343), with $\mathrm{x}$ indicating adjusted significant associations $(P<0.05)$.

In addition, multivariate regression analyses were performed for breast-feeding at every month from 1 to 5 months of age and from 7 to 11 months of age and the results are summarised in Table 6. Maternal education turned out to be the most stable variable as it was significantly associated with breast-feeding at all ages. Maternal age, maternal smoking, paternal education and infant birth weight also turned out to be stable variables as they showed significant associations with breast-feeding at most ages.

Factors associated with introduction of solid foods Ten per cent of the infants were introduced to solid foods before 4 months of age (i.e. at 3.5 months of age or earlier). In this group, the most common first food was porridge made of maize/rice/millet (63\% had consumed this), while $25 \%$ had consumed porridge made of oat/wheat/barley and $24 \%$ had consumed fruits/berries before the age of 4 months. Only a few had been introduced to vegetables, meat or yoghurt before 4 months of age.

A significant linear trend of increasing odds of not introducing solid foods before 4 months of age was found with increasing maternal education (Table 7). Girls had significantly higher odds of not being introduced to solid foods before 4 months of age than boys, and significant associations were also found for number of children and geographical region. The odds of not introducing solid foods before 4 months of age was significantly lower $(P<0 \cdot 001)$ for smoking mothers compared with nonsmoking mothers.

\section{Discussion}

Based on the data from a large national infant dietary survey, factors associated with exclusive breast-feeding and breast-feeding during the first year of life among Norwegian infants were explored. We found that exclusive breast-feeding and breast-feeding in early infant age overall were high. In multivariate regression analyses, exclusive breast-feeding was significantly associated with maternal education, while breast-feeding was significantly associated with maternal education and maternal age. Both exclusive breast-feeding and breast-feeding were negatively associated with maternal smoking.

\section{Exclusive breast-feeding and breast-feeding levels}

More than $90 \%$ of the infants in the present study were exclusively breast-fed at 1 week of age, and the level of exclusive breast-feeding was high during the first 3 months of life, but then declined to $10 \%$ at 6 months 
Table 5 Adjusted OR of breast-feeding at 6 and 12 months of age

\begin{tabular}{|c|c|c|c|c|c|c|c|c|}
\hline \multirow[b]{2}{*}{ Characteristics } & \multirow[b]{2}{*}{$n+$} & \multirow[b]{2}{*}{$\%+$} & \multicolumn{2}{|c|}{ Breast-feeding at 6 months } & \multirow[b]{2}{*}{$n+$} & \multirow[b]{2}{*}{$\%+$} & \multicolumn{2}{|c|}{ Breast-feeding at 12 months } \\
\hline & & & Adjusted OR $\ddagger$ & $95 \% \mathrm{Cl} \ddagger$ & & & Adjusted OR $\ddagger$ & $95 \% \mathrm{Cl} \ddagger$ \\
\hline \multicolumn{9}{|l|}{ Infant birth weight $(\mathrm{g})$} \\
\hline$>3500$ & 670 & 85 & $1 \cdot 00$ & - & 378 & 49 & $1 \cdot 00$ & - \\
\hline $2500-3500$ & 407 & 82 & 0.83 & $0 \cdot 60,1 \cdot 14$ & 213 & 45 & 0.85 & $0.67,1.08$ \\
\hline$<2500$ & 30 & 57 & $0 \cdot 19$ & $0 \cdot 11,0.36$ & 16 & 31 & 0.39 & $0.21,0.72$ \\
\hline$P$ trends & - & - & 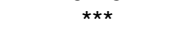 & - & - & - & * & - \\
\hline \multicolumn{9}{|l|}{ Maternal education } \\
\hline Primary and secondary schools & 33 & 61 & $1 \cdot 00$ & - & 13 & 26 & $1 \cdot 00$ & - \\
\hline Comprehensive school & 270 & 72 & 1.57 & $0.82,3.00$ & 136 & 38 & $1 \cdot 61$ & $0 \cdot 81,3 \cdot 21$ \\
\hline Academy/college/university ( $\leq 4$ years) & 456 & 86 & $2 \cdot 54$ & $1 \cdot 29,5 \cdot 01$ & 254 & 50 & $2 \cdot 33$ & $1 \cdot 17,4 \cdot 65$ \\
\hline Academy/college/university ( $>4$ years) & 348 & 91 & $3 \cdot 87$ & $1 \cdot 83,8 \cdot 17$ & 204 & 55 & $2 \cdot 81$ & $1.39,5 \cdot 66$ \\
\hline$P$ trend $\S$ & - & - & $\star \star * *$ & - & - & - & 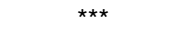 & - \\
\hline \multicolumn{9}{|l|}{ Paternal education } \\
\hline Primary and secondary schools & 78 & 81 & 1.00 & - & - & - & - & - \\
\hline Comprehensive school & 447 & 75 & 0.43 & $0.23,0.80$ & - & - & - & - \\
\hline Academy/college/university ( $\leq 4$ years) & 306 & 88 & $0 \cdot 72$ & $0.36,1.44$ & - & - & - & - \\
\hline Academy/college/university ( $>4$ years) & 276 & 90 & 0.73 & $0.35,1.55$ & - & - & - & - \\
\hline$P$ trend $\S$ & - & - & * & - & - & - & - & - \\
\hline \multicolumn{9}{|l|}{ Maternal age (years) } \\
\hline$\leq 24$ & 69 & 62 & $1 \cdot 00$ & - & 20 & 25 & 1.00 & - \\
\hline $25-34$ & 770 & 84 & 1.94 & $1 \cdot 21,3 \cdot 11$ & 395 & 47 & 1.99 & $1 \cdot 13,3 \cdot 50$ \\
\hline$\geq 35$ & 268 & 84 & $1 \cdot 80$ & $1 \cdot 04,3 \cdot 11$ & 192 & 53 & $2 \cdot 40$ & $1 \cdot 30,4 \cdot 44$ \\
\hline$P$ trend $\S$ & - & - & NS & - & - & - & * & - \\
\hline \multicolumn{9}{|l|}{ Maternal smoking } \\
\hline No & 1001 & 86 & 1.00 & - & 559 & 50 & $1 \cdot 00$ & - \\
\hline Yes & 106 & 60 & 0.35 & $0.24,0.51$ & 48 & 29 & 0.49 & $0.34,0.71$ \\
\hline \multicolumn{9}{|l|}{ Maternal marital status } \\
\hline Married & 547 & 85 & $1 \cdot 00$ & - & - & - & - & - \\
\hline Cohabitant & 533 & 81 & 1.05 & $0 \cdot 76,1 \cdot 44$ & - & - & - & - \\
\hline Not married/cohabitant & 27 & 61 & 0.43 & $0.21,0.88$ & - & - & - & - \\
\hline \multicolumn{9}{|l|}{ Number of children } \\
\hline 1 & - & - & - & - & 234 & 47 & $1 \cdot 00$ & - \\
\hline 2 & - & - & - & - & 232 & 44 & 0.75 & $0.57,0.97$ \\
\hline$\geq 3$ & - & - & - & - & 141 & 55 & $1 \cdot 12$ & $0.79,1.58$ \\
\hline & - & - & - & - & - & - & NS & - \\
\hline \multicolumn{9}{|l|}{ Day care by persons other than the parents } \\
\hline No & - & - & - & - & 454 & 50 & $1 \cdot 00$ & - \\
\hline Yes & - & - & - & - & 153 & 40 & 0.64 & $0.50,0.82$ \\
\hline
\end{tabular}

tNumber and percentage of breast-fed infants within the current independent variable. Total number of infants at 6 ( $n$ 1343) and at 12 ( $n$ 1285) months of age. fOR and $95 \% \mathrm{Cl}$ are adjusted for all other variables in the table, with the exception of day care by persons other than the parents at 6 months of age. §Test for linear trend: NS; ${ }^{\star} P<0.05,{ }^{* \star} P<0.01,{ }^{* \star} P<0.001$.

of age. These data are consistent with earlier national data from Norway ${ }^{(14)}$. National data from Sweden show the same level of exclusive breast-feeding at 1 week of age compared to our findings (88\%), while $15 \%$ of the infants were exclusively breast-fed at 6 months of age ${ }^{(17)}$. In the USA, national data show a low level of exclusive breastfeeding at 1 week of age ( $50 \%$ ), while $14 \%$ of the infants were exclusively breast-fed at 6 months of age ${ }^{(18)}$.

Only $1.5 \%$ of the infants in our study had never been breast-fed. Breast-feeding level slowly decreased from $92 \%$ at 2 months of age, to $82 \%$ at 6 months and further down to $46 \%$ at 12 months of age. A high level of breast-feeding initiation has also been reported in Sweden where 98\% of the mothers initiated breast-feeding ${ }^{(17)}$. At 2 months of age, $90 \%$ were breast-fed, while $69 \%$ and $17 \%$ of the infants were breast-fed at 6 and 12 months of age, respectively ${ }^{(17)}$. The breast-feeding initiation reported from the USA was $74 \%$ and at 2, 6 and 12 months of age the corresponding breastfeeding rates were $63 \%, 43 \%$ and $23 \%$, respectively ${ }^{(18)}$.

\section{Maternal and paternal education}

A number of studies have observed that maternal education is significantly associated with exclusive breastfeeding and breast-feeding duration ${ }^{(4,5,7,8,19-21)}$. In our study, the odds of exclusive breast-feeding and breastfeeding increased significantly with increasing maternal educational level. We found a significant association between exclusive breast-feeding at 4 months of age and paternal education, but no significant association was found at 5.5 months of age. In the AIBS study (All Babies in Southeast Sweden), data on exclusive breast-feeding were available for more than 10000 infants born between 1997 and $1999^{(7)}$, and low paternal education was reported to be a risk factor for short exclusive breast-feeding $(<4$ months). Paternal education was found to be significantly associated with breast-feeding at every month from 2 to 9 months of age in the present study. In a study among 10500 Californian women, Heck et $a l^{(22)}$ showed positive associations between breast-feeding and paternal education, 


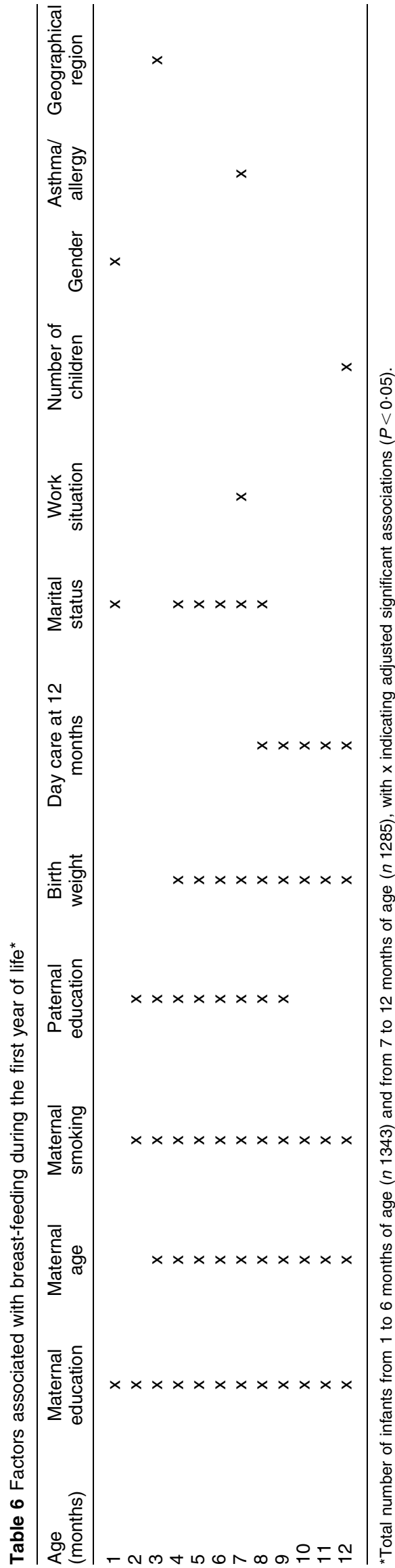

and Lanting et $a l^{(20)}$ reported that women in The Netherlands who initiated breast-feeding were more likely to have a higher-educated partner.

\section{Maternal age}

Maternal age is a powerful variable that has been associated with exclusive breast-feeding and breast-feeding initiation and duration ${ }^{(3-5,7)}$. In contrast to what others have reported $^{(6,7)}$, we did not find a significant association between exclusive breast-feeding and increasing maternal age at 4 months of age. However, at 5.5 months of age a significant association was observed. In the present study, multivariate analyses of breast-feeding during the first year of life showed that maternal age turned out to be a stable variable as it was significantly associated with breast-feeding at every month from 3 to 12 months of age.

\section{Maternal smoking}

In Sweden, Ludvigsson and Ludvigsson ${ }^{(7)}$ reported smoking to be associated with increased risk of short exclusive breast-feeding ( $<4$ months). In the previous national dietary survey among infants in Norway, Lande et $a l^{(6)}$ reported significantly lower odds of exclusive breast-feeding at 4 months of age for mothers who smoked compared with non-smoking mothers (adjusted $\mathrm{OR}=0 \cdot 40 ; 95 \% \mathrm{CI} 0 \cdot 32,0 \cdot 50)$. This is similar to the results we observed for maternal smoking with regard to exclusive breast-feeding at 4 and 5.5 months of age.

In the present study, maternal smoking was an important adverse factor on the duration of breast-feeding. The odds of breast-feeding at both 6 and 12 months of age were lower for mothers who smoked compared with non-smoking mothers. For breast-feeding duration and maternal smoking, a consistent negative association has been reported in the literature ${ }^{(3-5,23)}$.

In our analyses, maternal smoking turned out to be a stable variable as it was negatively associated with exclusive breast-feeding at every month from 3 to 5.5 months of age and with breast-feeding from 2 to 12 months of age.

\section{Marital status}

We found a significant association between marital status and breast-feeding at 6 months of age, but no such association was observed for breast-feeding at 12 months of age or for exclusive breast-feeding at 4 or 5.5 months of age. Some studies have shown that breast-feeding occurs more frequently among married women and that married women breast-feed for longer periods of time ${ }^{(5)}$, while others have not found this association ${ }^{(4)}$.

\section{Birth weight}

We found no significant association between infant birth weight and exclusive breast-feeding; however, the odds of breast-feeding decreased significantly with decreasing birth weight at both 6 and 12 months of age. The same was observed by Lande et al. $^{(6)}$. 
Table 7 Adjusted OR of not receiving solid foods before 4 months of age

\begin{tabular}{|c|c|c|c|c|}
\hline \multirow[b]{2}{*}{ Characteristics } & \multirow[b]{2}{*}{$n+$} & \multirow[b]{2}{*}{$\% \dagger$} & \multicolumn{2}{|c|}{$\begin{array}{l}\text { Not receiving solid foods before } \\
\qquad 4 \text { months }\end{array}$} \\
\hline & & & Adjusted OR & $95 \% \mathrm{Cl}$ \\
\hline \multicolumn{5}{|l|}{ Infant's gender } \\
\hline Boy & 582 & 88 & $1 \cdot 00$ & - \\
\hline Girl & 624 & 92 & $1 \cdot 58$ & $1 \cdot 08,2 \cdot 31$ \\
\hline \multicolumn{5}{|l|}{ Maternal education } \\
\hline Primary and secondary schools & 41 & 76 & $1 \cdot 00$ & - \\
\hline Comprehensive school & 315 & 84 & $1 \cdot 36$ & $0 \cdot 65,2 \cdot 82$ \\
\hline Academy/college/university ( $\leq 4$ years) & 485 & 91 & $2 \cdot 02$ & $0.94,4.33$ \\
\hline Academy/college/university ( $>4$ years) & 365 & 95 & 3.68 & $1 \cdot 57,8.67$ \\
\hline$P$ trend§ & - & - & 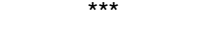 & - \\
\hline \multicolumn{5}{|l|}{ Maternal age (years) } \\
\hline$\leq 24$ & 82 & 74 & $1 \cdot 00$ & - \\
\hline $25-34$ & 828 & 91 & $1 \cdot 66$ & $0 \cdot 95,2 \cdot 88$ \\
\hline$\geq 35$ & 296 & 93 & $1 \cdot 88$ & $0.91,3.91$ \\
\hline$P$ trend & - & - & NS & - \\
\hline \multicolumn{5}{|l|}{ Maternal smoking } \\
\hline No & 1069 & 92 & $1 \cdot 00$ & - \\
\hline Yes & 137 & 78 & $0 \cdot 45$ & $0 \cdot 28,0 \cdot 70$ \\
\hline \multicolumn{5}{|l|}{ Number of children } \\
\hline 1 & 462 & 86 & $1 \cdot 00$ & - \\
\hline 2 & 509 & 93 & $2 \cdot 00$ & $1 \cdot 29,3 \cdot 12$ \\
\hline$\geq 3$ & 235 & 91 & $1 \cdot 51$ & $0 \cdot 86,2 \cdot 66$ \\
\hline$P$ trend $\S$ & - & - & * & - \\
\hline \multicolumn{5}{|l|}{ Geographical region } \\
\hline Capital and surroundings & 304 & 93 & $1 \cdot 00$ & - \\
\hline East & 299 & 89 & $0 \cdot 71$ & $0 \cdot 40,1 \cdot 25$ \\
\hline South & 193 & 92 & $1 \cdot 06$ & $0 \cdot 53,2 \cdot 11$ \\
\hline West & 205 & 92 & $1 \cdot 06$ & $0.54,2 \cdot 07$ \\
\hline Middle & 104 & 87 & $0 \cdot 61$ & $0 \cdot 30,1 \cdot 24$ \\
\hline North & 101 & 80 & $0 \cdot 32$ & $0.17,0.62$ \\
\hline
\end{tabular}

tNumber and percentage of infants not receiving solid foods before 4 months of age within current independent variable. Total number of infants $(n$ 1343).

fOR and $95 \% \mathrm{Cl}$ are adjusted for all other variables in the table.

$\S$ Test for linear trend: NS; ${ }^{*} P<0 \cdot 05,{ }^{\star \star} P<0 \cdot 01,{ }^{\star \star \star} P<0 \cdot 001$.

\section{Parity}

In the literature, the association between parity and breast-feeding is inconsistent ${ }^{(4,5)}$. In our study, the odds of exclusive breast-feeding at 4 months of age increased with increasing number of children. We did not observe a consistent pattern between exclusive breast-feeding or breast-feeding and parity.

\section{Day care}

Due to the Norwegian parental leave system, the majority of Norwegian infants are in parental care at the first year of life. At the age of 12 months, $70 \%$ of the infants in our study were in parental care, while $30 \%$ were taken care of by childminders, kindergartens, grandparents or other care persons. For breast-feeding at 12 months of age, we observed a significant negative association with nonparental day care and observed that infants who had non-parental care had lower odds of being breast-fed at this age. A recent study from the USA ${ }^{(24)}$, using a national representative sample of 8150 infants, reported that infants who attended day care before 3 months of age were less likely to ever have been breast-fed than those in parental care. In another national sample of 2500 mothers in the USA, Hendricks et al. ${ }^{(25)}$ observed that being in day care was associated with decreased duration of breastfeeding at ages 6 and 12 months.

\section{Introduction of solid foods}

Norwegian health authorities recommend that solid foods are introduced at 6 months of age, or at the earliest at 4 months of age ${ }^{(11)}$. In the present study, $10 \%$ had been introduced to solid foods before 4 months of age. National data from the USA ${ }^{(26)}$ show that about $29 \%$ of all infants were introduced to solid foods before 4 months of age, while earlier national data from Norway ${ }^{(6)}$ observed that $21 \%$ of the infants received solid foods before the age of 4 months; the corresponding percentages reported from Sweden and Switzerland are $4 \%$ and $5 \%$, respectively ${ }^{(27,28)}$.

Consistent with earlier findings from Norway, we found that infants with mothers who were less educated were more likely to have been introduced to solid foods before 4 months of age and that the introduction of solid foods differed significantly among geographical regions ${ }^{(6)}$. In the univariate analysis the odds of timely introduction of solid foods increased with increasing maternal age, but in contrast to earlier findings ${ }^{(6,25,29)}$, this association was not significant in the multivariate analysis. Moreover, a significant 
association between the introduction of solid foods and parity was observed in the present study. Compared to associations reported in the literature, some have found an association ${ }^{(6,30)}$, while others have not ${ }^{(29,31)}$. In our study, boys were more likely to be introduced to solid foods before 4 months of age than girls. Lande et al. ${ }^{(6)}$ and Erkkola et al. ${ }^{(29)}$ reported similar results, while Scott et al. did not find such association ${ }^{(31)}$. We found that mothers who smoked were more likely than non-smoking mothers to introduce solid foods early, and this is consistent with what others have reported ${ }^{(6,28,31)}$.

In the present study, we used national representative data from 1490 mothers/infants who participated in a prospective cohort study in Norway. The response rate was $52 \%$. When comparing the responders with available data on all Norwegian births in 2006, there were no indications of differences regarding an infant's gender, gestational age, number of children, geographical region or maternal marital status. Small differences, which were considered unimportant, were seen for maternal age and infant birth weight, e.g. the average maternal age in our cohort was 1 year higher than the average age of all mothers giving birth that year. The only information we had on the non-responders was geographical region, and this did not differ from the responders.

Data on exclusive breast-feeding and breast-feeding practices were collected retrospectively, but within a maximum of 6 months after cessation. Li et al. ${ }^{(32)}$ concluded in their review that mothers seems to provide accurate estimates of initiation and duration of any breastfeeding, especially when the duration is recalled over a period of 3 years or less. The validity and reliability of maternal recall for the age at introduction of foods and fluids other than breast milk seems to be less satisfactory $^{(32)}$. We used several questions to assess exclusive breast-feeding, breast-feeding and introduction of solid foods, but we cannot fully exclude recall bias.

For exclusive breast-feeding at 4 months of age, we observed a tendency towards stronger effects of maternal age on the number of children in the lowest age groups compared with those in the highest age groups. For breast-feeding at 6 months of age we observed a tendency towards stronger effects of maternal age on infant birth weight among mothers in the age group 25-34 years compared with the two other age groups. For breastfeeding at 6 months of age we also observed a tendency towards stronger effects of maternal smoking among mothers in the lowest educational groups compared with the higher educational groups (data not shown). These interactions need to be investigated further.

\section{Conclusion}

Even though Norway has an extensive and positive breastfeeding tradition and a maternal leave system which support the possibility to breast-feed, factors like maternal education, maternal age and maternal smoking are strongly associated with duration of exclusive breast-feeding and breast-feeding. Research to better understand the reasons for inequalities in breast-feeding is needed to facilitate the development of more effective breast-feeding promotion strategies. This, again, may improve compliance with recommendations and reduce inequalities in infant feeding practices.

\section{Acknowledgements}

The present study was generously supported by EXTRA funds from the Norwegian Foundation for Health and Rehabilitation. The authors declare no conflict of interest. A.L.K. carried out the data analyses and wrote the manuscript; B.L., N.C. $\varnothing$. and L.F.A. assisted and provided advice during all the stages of the work. All authors contributed in the discussion and interpretation of the results, and in the drafting and editing of the manuscript. The authors are grateful to all children and their parents who participated in the national dietary survey 'Spedkost 2006-2007'. They thank all health professionals who assisted the parents in getting data on the infants' weight and height, and also thank Tron Anders Moger who provided advice for the statistical analyses.

\section{References}

1. Duijts L, Ramadhani MK \& Moll HA (2009) Breastfeeding protects against infectious diseases during infancy in industrialized countries. A systematic review. Matern Child Nutr 5, 199-210.

2. Ip S, Chung M, Raman G et al. (2007) Breastfeeding and maternal and infant health outcomes in developed countries. Evid Rep Technol Assess (Full Rep) 153, 1-186.

3. Dennis CL (2002) Breastfeeding initiation and duration: a 1990-2000 literature review. J Obstet Gynecol Neonatal Nurs 31, 12-32.

4. Scott JA \& Binns CW (1999) Factors associated with the initiation and duration of breastfeeding: a review of the literature. Breastfeed Rev 7, 5-16.

5. Thulier D \& Mercer J (2009) Variables associated with breastfeeding duration. J Obstet Gynecol Neonatal Nurs 38, 259-268.

6. Lande B, Andersen LF, Baerug A et al. (2003) Infant feeding practices and associated factors in the first six months of life: the Norwegian infant nutrition survey. Acta Paediatr 92, 152-161.

7. Ludvigsson JF \& Ludvigsson J (2005) Socio-economic determinants, maternal smoking and coffee consumption, and exclusive breastfeeding in 10205 children. Acta Paediatr 94, 1310-1319.

8. Michaelsen KF, Larsen PS, Thomsen BL et al. (1994) The Copenhagen cohort study on infant nutrition and growth: duration of breast feeding and influencing factors. Acta Paediatr 83, 565-571.

9. World Health Organization (2001) The Optimal Duration of Exclusive Breastfeeding. Report of An Expert Consultation. Geneva: WHO.

10. World Health Organization (2008) Indicators for Assessing Infant and Young Child Feeding Practices. Conclusions of 
a Consensus Meeting held 6-8 November 2007 in Washington DC, USA. Geneva: WHO.

11. Norwegian Directorate of Health (2001) Infant Feeding Recommendations. Report no. IS-1019. Oslo: Norwegian Directorate of Health.

12. Liestol K, Rosenberg M \& Walloe L (1988) Breast-feeding practice in Norway 1860-1984. J Biosoc Sci 20, 45-58.

13. NAV (not dated) Parental benefit on birth. http://www. nav.no/English/Stay+in+Norway/805369034.cms (accessed August 2009).

14. Lande B (2003) Spedkost 6 Months - Norwegian National Dietary Survey Among Infants at 6 Months. Report no. IS-1074. Oslo: Norwegian Directorate of Health.

15. Lande B \& Andersen LF (2005) Spedkost 12 Months Norwegian National Dietary Survey among Infants. Report no. IS-1248. Oslo: Norwegian Directorate of Health.

16. Andersen LF, Lande B, Arsky GH et al. (2003) Validation of a semi-quantitative food-frequency questionnaire used among 12-month-old Norwegian infants. Eur J Clin Nutr 57, 881-888.

17. National Board of Health and Welfare (2008) Breastfeeding, Children born in 2006. http://www.socialstyrelsen.se/ publikationer2008/2008-125-12 (accessed September 2009).

18. National Immunization Survey, Centers for Disease Control and Prevention, Department of Health and Human Services (2006) US National Breastfeeding Rates. http://www.cdc. gov/breastfeeding/data/NIS_data/2006/age.htm (accessed October 2006).

19. Susin LR, Giugliani ER, Kummer SC et al. (1999) Does parental breastfeeding knowledge increase breastfeeding rates? Birth 26, 149-156.

20. Lanting CI, Van Wouwe JP \& Reijneveld SA (2005) Infant milk feeding practices in the Netherlands and associated factors. Acta Paediatr 94, 935-942.

21. Yngve A \& Sjostrom M (2001) Breastfeeding determinants and a suggested framework for action in Europe. Public Health Nutr 4, 729-739.
22. Heck KE, Braveman P, Cubbin C et al. (2006) Socioeconomic status and breastfeeding initiation among California mothers. Public Health Rep 121, 51-59.

23. Horta BL, Kramer MS \& Platt RW (2001) Maternal smoking and the risk of early weaning: a meta-analysis. Am J Public Health 91, 304-307.

24. Kim J \& Peterson KE (2008) Association of infant child care with infant feeding practices and weight gain among US infants. Arch Pediatr Adolesc Med 162, 627-633.

25. Hendricks K, Briefel R, Novak T et al. (2006) Maternal and child characteristics associated with infant and toddler feeding practices. J Am Diet Assoc 106, Suppl. 1, S135-S148.

26. Briefel RR, Reidy K, Karwe V et al. (2004) Feeding infants and toddlers study: improvements needed in meeting infant feeding recommendations. J Am Diet Assoc 104, Suppl. 1, S31-S37.

27. Brekke HK, Ludvigsson JF, van OJ et al. (2005) Breastfeeding and introduction of solid foods in Swedish infants: the All Babies in Southeast Sweden study. Br J Nutr 94, 377-382.

28. Dratva J, Merten S \& Ackermann-Liebrich U (2006) The timing of complementary feeding of infants in Switzerland: compliance with the Swiss and the WHO guidelines. Acta Paediatr 95, 818-825.

29. Erkkola M, Pigg HM, Virta-Autio P et al. (2005) Infant feeding patterns in the Finnish type I diabetes prediction and prevention nutrition study cohort. Eur J Clin Nutr 59, 107-113.

30. Tatone-Tokuda F, Dubois L \& Girard M (2009) Psychosocial determinants of the early introduction of complementary foods. Health Educ Behav 36, 302-320.

31. Scott JA, Binns CW, Graham KI et al. (2009) Predictors of the early introduction of solid foods in infants: results of a cohort study. BMC Pediatr 9, 60.

32. Li R, Scanlon KS \& Serdula MK (2005) The validity and reliability of maternal recall of breastfeeding practice. Nutr Rev 63, 103-110. 